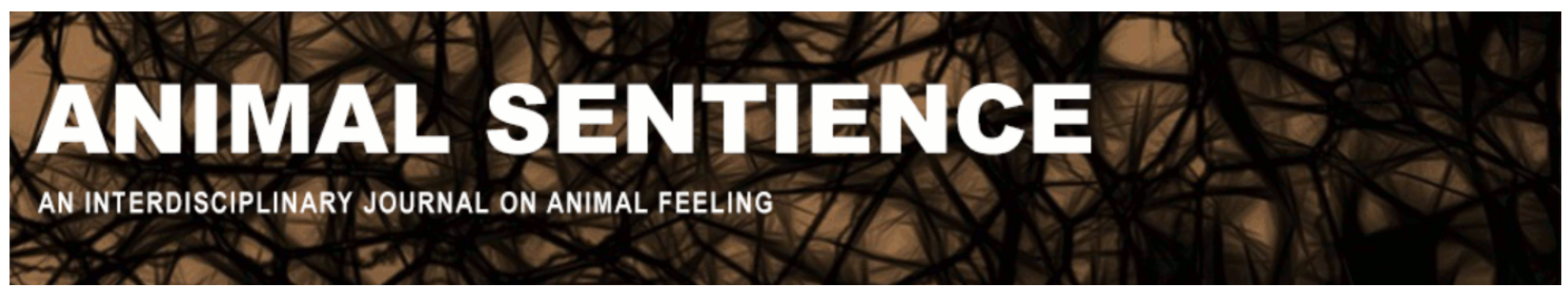

Mather, Jennifer A. (2016) An invertebrate perspective on pain. Animal Sentience $3(12)$

DOI: $10.51291 / 2377-7478.1046$

Date of submission: $2015-10-21$

Date of acceptance: 2015-12-13

(c)

This article has appeared in the journal Animal

Sentience, a peer-reviewed journal on animal

cognition and feeling. It has been made open access,

free for all, by WellBeing International and deposited

in the WBI Studies Repository. For more information,

please contact

wbisr-info@wellbeingintl.org.

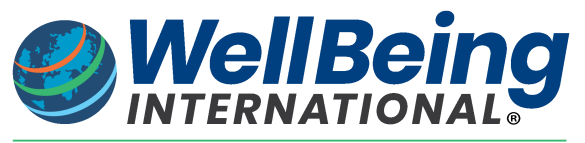

SOLUTIONS FOR PEOPLE, ANIMALS AND ENVIRONMENT 


\title{
An invertebrate perspective on pain
}

Commentary on Key on Fish Pain

\author{
Jennifer A. Mather \\ Department of Psychology \\ University of Lethbridge
}

\begin{abstract}
Although Key (2016) argues that mammals feel pain and fish do not, from an invertebrate perspective, it is obvious that the pain experience is shared by animals from a number of different animal groups.
\end{abstract}

Jennifer Mather mather@uleth.ca is Professor in the Department of Psychology at University of Lethbridge. She has published many articles on cephalopod behavior and intelligence and is reguarded as an authority on ethics with regard to cephalopods. http://directory.uleth.ca/users/mather

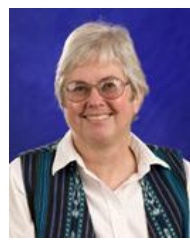

Professor Key (2016) has addressed an interesting area of research, the perception of pain. But he has focused on a narrow and divisive approach - the comparison of pain in humans and fish - with the intent to prove that fish don't feel pain. He starts off with an illogical premise. We have a cortex, and firing of specific areas in it likely causes the signals we feel as pain. Fish do not have this cortex, and therefore cannot feel pain. But "if a then b" does not mean "if not a, then not b." Evolution has produced many analogies, when different structures lead to similar functions in disparate groups. Preserving bodily integrity is so important to animals that such mechanisms should evolve in many different groups - mammals, birds (which he does not mention), fish and even invertebrates.

Not all animals react to noxious stimuli with responses that we call pain. Key suggests that some animals "lack the necessary neural "hardware' to feel pain" and we typically describe these species as having only "nociception." Our difficulty comes in trying to decide whether a particular species or group has such neural hardware, since many "lower" animals have relatively automatic and stereotyped behavioural responses. Key relies on humans' ability to say that they do feel pain; they are "the only species able to directly report on its feelings." Nonhuman animals do not have speech, so we are forced to rely on behavioural evidence of cognitive complexity and consciousness. Key believes that such evidence is unreliable when applied to "lower" animals, yet such evidence is abundant both in fish and in some invertebrates. Besides, speech is not necessarily an accurate report of actions; in the study of motivation, psychologists rely on what we do and not what we say. 
Such widespread cognitive ability, if demonstrated, suggests that many animals without a cortex have structures analgous to, though probably not as complex as, the mammalian cortex. Therefore, we can assume they feel some kind of pain. Contrary to Key's assumption that fish, and presumably other "lower" animals, have only "automatic S-R schemata," evidence of their behavioural variability is abundant. For examples of fish, see Brown, Laland and Krause (2011; especially the chapter by Bshary). Braithwaite's (2010) application of this variability of fish behavior in response to noxious stimuli is also convincing.

But what of even "lower" invertebrate animals? Can we assume they "feel pain"? The necessary capacity would be a centralized brain, cognitive ability and the possibility of consciousness the opposite of "automatic schemata." This might be demonstrated by variability in response to any situation, noxious stimuli included, and by long-term learning, situational trade-offs and tending of a wound, indicating both localization and awareness of damage mitigation. We do not expect the exact replication of mammalian pain responses, as such a capacity is probably on a behavioral continuum.

Cephalopod mollusks are the model for variability in behavior of invertebrates (Darmaillacq, Dickel \& Mather, 2014). Octopuses especially respond to novel situations with exploration and even play (Mather \& Anderson, 1999). Mather (2008) has speculated, based on this behavioural flexibility, that they may have simple consciousness. Researchers have catalogued octopus responses to the stinging nematocysts of Cnidarian sea anemones, which cause pain sensations in humans. Rather than any automatic response, octopuses confronted with sea anemones tried "cautious" approaches, coming at the animal from a different direction and even blowing jets of water at the anemone as if to dislodge it (Mather, 2013).

What if cephalopods are exposed to stimuli that would cause pain in vertebrates? Crook, Lewis, Hanlon and Walters (2011) cut off the distal 1/3 of the arm of un-anesthetized Loligo squid and immediately released the animals back into the water. Squid subsequently were more sensitive both to anticipation of touch and touch itself. This was particularly true for jets of water at the stimulus and defensive release of ink, as well as longer distance escape jets. Crook, Hanlon and Walters (2013) located nociceptors whose lowered threshold persisted for over 30 minutes, as would be found in mammalian pain receptors. This sensitivity was general across the body, not localized. In octopuses, however, a noxious crush stimulus to the arm lowered the touch threshold predominantly to the injured arm, and such sensitization continued for 24 hours (Alupay, Hadjisolomou \& Crook, 2014). Interestingly, after injury the octopus groomed an arm for the first 10-20 minutes and then held it close to the body, with half the animals curling other arms around the injured one.

Evidence for cognitive abilities in crustaceans is more limited than in octopuses, though Elwood (1995) studied evaluating and occupying mollusk shells by hermit crabs. Elwood (2013) summarizes the studies suggesting pain, including trade-off between occupancy of "quality" 
shells and avoidance of a minimal electrical shock delivered from the shell, influenced also by exposure to the odour of a predator. Crabs also rub affected areas, as do octopuses - and humans. Shore crabs avoid a preferred dark shelter paired with a shock and discriminate between similar shelters different in terms of shock, based on the location (Magee \& Elwood, 2013). These reactions are consistent not with reflexive stimuli but with vertebrate "pain experience."

Kay has observed that we can never prove that any specific animal group doesn't have pain at all, and similarly we can never definitively prove it does. Given the widespread occurrence of pain-like experiences, we should explore their capacities rather than delineate "haves" versus "have-nots." Animals are not all alike, and pain may be processed differently in octopuses, birds and humans. So let's explore those experiences and discover the commonalities and differences, rather than setting up opposites.

\section{References}

Alupay, J. S., Hadjisolomou, S. P. \& Crook, R. J. (2014). Arm injury produces long-term behavioral and neural hypersensitivity in octopus. Neuroscience Letters, 558, 137-142.

Braithwaite, V. (2010). Do fish feel pain? New York, NY: Oxford University Press.

Brown, C., Laland, K. \& Krause, J., Eds. (2011). Fish cognition and behavior, $2^{\text {nd }}$ ed. Chichester, UK: Wiley-Blackwell.

Crook, R. J., Hanlon, R. T. \& Walters, E. T. (2013). Squid have nociceptors that display widespread long-term sensitization and spontaneous activity after bodily injury. The Journal of Neuroscience, 33, 10021-10026.

Crook, R. J., Lewis, T., Hanlon, R. T. \& Walters, E. T. (2011). Peripheral injury induces long-term sensitization of defensive responses to visual and tactile stimuli in the squid Loligo pealeii, Lesueur 1821. The Journal of Experimental Biology, 214, 3173-3185.

Darmaillacq, A-S, Dickel, L. \& Mather, J. A., Eds. (2014). Cephalopod cognition. Cambridge, UK: Cambridge University Press.

Elwood, R. W. (1995). Motivational change during resource assessment by hermit crabs. Journal of Experimental Marine Biology and Ecology, 193, 41-55.

Elwood, R. W. (2013). Can we infer pain in crustaceans from behavior experiments? In Animal suffering: From science to law, T. A. van der Kemp \& M. Lachance (Eds.), pp. 125-134. Toronto, Canada: Carswell. 
Key, B. (2016). Why fish do not feel pain. Animal Sentience 2016.003.

Magee, B. \& Elwood, R. W. (2013). Shock avoidance by discrimination learning in the shore crab (Carcinus maenas) is consistent with a key criterion for pain. The Journal of Experimental Biology, 216, 353-358.

Mather, J. A. (2008). Cephalopod consciousness: behavioral evidence. Consciousness and Cognition, 17, 37-48.

Mather, J. A. (2013). Do cephalopods have pain and suffering? In Animal suffering: From science to law, T. A. van der Kemp \& M. Lachance (Eds.), pp. 113-124. Toronto, Canada: Carswell.

Mather, J. A. \& Anderson R. C. (1999). Exploration, play and habituation in Octopus dofleini. Journal of Comparative Psychology, 113, 333-338. 